\title{
Betulinic acid-induced expression of nicotinamide adenine dinucleotide phosphate-diaphorase in the immune organs of mice: A possible role of nitric oxide in immunomodulation
}

\author{
KAI LE PANG $^{1 *}$, KAVITHA VIJAYARAGHAVAN ${ }^{2}$, BADR AL SAYED $^{3}$ and MOHAMED ALI SEYED ${ }^{3 *}$ \\ ${ }^{1}$ Faculty of Pharmacy, Universiti, Kebangsaan Malaysia (UKM), The National University of Malaysia, \\ Kuala Lumpur 50300, Malaysia; ${ }^{2}$ Agni College of Technology, Thalambur, Chennai 600 130, India; \\ ${ }^{3}$ Faculty of Medicine, University of Tabuk, Tabuk 71491, Saudi Arabia
}

Received July 5, 2017; Accepted October 30, 2017

DOI: $10.3892 / \mathrm{mmr} .2017 .8262$

\begin{abstract}
The aim of the present study was to investigate the effects of betulinic acid (BetA) on the expression and distribution pattern of nicotinamide adenine dinucleotide phosphate diaphorase (NADPH-d), an indirect indicator of nitric oxide (NO) synthase in the thymus and spleen of mice. Mice were randomly assigned to four main groups $(n=48$ per group): Experimental group (BetA), positive control group (goniothalamin), vehicle control group (dimethyl sulfoxide) and control group (without vehicle). Each group was further divided into three equal subgroups according to the treatment length (4, 8 and 12 days). BetA treatment induced the expression of NADPH-d activity in the thymus and spleen without any significant changes in the morphology of the organs. Furthermore, the expression pattern of NADPH-d in BetA-treated animals was significantly increased compared with that in the control animals. NADPH-d expression in the thymus and spleen suggests that NO signaling may be a potential mechanism underlying the BetA-induced immunomodulation in these organs. These findings are of direct clinical relevance and may contribute to the further development of BetA as a therapeutic drug.
\end{abstract}

\section{Introduction}

Numerous diseases, including cancer require modulation in the immune system for disease management and care (1). Under the circumstance of weakened immune responsiveness,

Correspondence to: Professor Mohamed Ali Seyed, Faculty of Medicine, University of Tabuk, 1 Tabuk Duba Main Road, Tabuk 71491, Saudi Arabia

E-mail: sdmdali.ali@gmail.com

*Contributed equally

Key words: nicotinamide adenine dinucleotide phosphate diaphorase, nitric oxide, betulinic acid, mice, thymus, spleen the host protection machinery has to be activated to provide an alternative to conventional chemotherapy (2). Potential immunomodulatory agents $(3,4)$ have been identified based on the observed therapeutic effects of phytochemicals isolated from various plants (5-7), and segregates of microorganisms and mammalian proteins, including immune mediators and certain synthetic chemicals (8).

The triterpene alcohol, betulin and its equivalent carboxylic acid, betulinic acid (BetA; Fig. 1) are isolated from betula birch bark (9), which has been used for various medicinal purposes in many countries (10). BetA is a pentacyclic lupane-type triterpenoid of which a wide range of biological properties have been shown against cancer, inflammation, malaria, and helmintic and viral activities (11-14). Among these, the anticancer and cytotoxic activities of BetA have received significant attention $(15,16)$. Selective cytotoxicity has been demonstrated in multiple tumor cell lines (15-19) without effect in normal cells, including dermal fibroblasts and peripheral blood lymphocytes (20-22). Furthermore, no systemic toxic effects have been observed in rodents (23). However, BetA is considered to be a weak antineoplastic agent, as it is required at micromolar concentrations to inhibit cell proliferation in vitro, and even higher doses are required ( $250 \mathrm{mg} / \mathrm{kg}$ body weight) to control melanoma growth in athymic mice (24).

Despite a lack of toxicity, the poor potency of BetA hinders its clinical development. Mullauer et al (23) cautioned that existing in vivo data are insufficient to support that BetA does not cause an effect on healthy cells. Furthermore, in contrast to previous findings, a recent study by Heiss et al (24) reported that $10 \mu \mathrm{M}$ BetA induces changes in normal cellular metabolism. The study by Heiss et al (24) raised concerns regarding the clinical application of BetA and prompted us to investigate whether BetA may cause any major effects on healthy cells in the immune organs of mice.

Nitric oxide (NO) is a free radical and ubiquitous signaling molecule $(25,26)$ present in immune and endocrine tissues, among others (27-29) and a well-known mediator in numerous therapeutic and immuomodulatory functions, indicating a regulatory function of NO in primary and secondary immune organs. There are three isoforms of NO synthases (NOSs), 
which are neuronal (nNOS), inducible (iNOS) and endothelial (eNOS), and they are responsible for the synthesis of NO from the amino acid, l-arginine (30). Previous studies have demonstrated that all three isoforms express enzymatic activity of NADPH-d $(31,32)$, and indicated the expression pattern of $\mathrm{NADPH}-\mathrm{d}$ is an indirect indication of the presence of NOS and NO $(30,33)$. Therefore NADPH-d activity has been used as a marker for NOS.

Therefore, the current study was performed to determine whether $10 \mu \mathrm{M}$ BetA modulates NO production or induces changes in healthy spleen and thymus cells in mice, and to investigate the possible functions of BetA in these organs. A histochemical analysis of NADPH-d, a marker for NOS, was also performed (34).

\section{Materials and methods}

Animals and reagents. Animal experiments were conducted in accordance with the National University of Malaysia (UKM; Kuala Lumpur, Malaysia) animal ethics guidelines and regulations laid out by the Institutional Animal Ethics Committee (UKMAEC; FF/2016/ALI/20-MAY/685-JUNE-2016). Six-week-old, female BALB/c mice procured from the institutional animal holding facility $(\mathrm{n}=196)$, were maintained (2-3 animals/cage) under pathogen-free conditions and a 12-h light/dark cycle, with access to commercial pellets and distilled water. BetA (Sigma-Aldrich; Merck KGaA, Darmstadt, Germany) served as a test drug, goniothalamin (GTN; provided by Dr Ibrahim Jantan, Faculty of Pharmacy, UKM) served as a positive control drug, and dimethyl sulfoxide (DMSO; Merck $\mathrm{KGaA}$ ) served as a vehicle.

Animal treatment and sample collection. Animals were randomly divided into four main groups as follows: Experimental group (10 $\mu \mathrm{M}$ BetA; $\mathrm{n}=48)$, a positive control group (50 $\mu \mathrm{M}$ GTN; $\mathrm{n}=48)$, a negative control group $(0.05 \%$ DMSO; $n=48)$ and a normal standard control group $(n=48)$. Each main group of animals was further divided into three equal subgroups ( $\mathrm{n}=6$ per group) corresponding to the treatment period (4, 8 and 12 days). Chloral hydrate (10\%; i.p.) was administered to anesthetize the animals, subsequently animals were fixed using $4 \%$ paraformaldehyde and a transcardiac perfusion method described by Syed et al (27). The fixed tissue blocks were maintained in the same fixative solution for a further $6 \mathrm{~h}$ as post fixation, followed by rinsing in $0.1 \mathrm{M}$ phosphate buffer (PB) and cryoprotection in 30\% sucrose. Finally, $10 \mu \mathrm{m}$ frozen sections were sliced (Leica SM2010 Sliding microtome; Leica Microsystems GmbH, Wetzlar, Germany). Three series of sliced sections were collected on a glass slide and stained for NADPH-d.

Histochemistry of NADPH-d and analysis of tissue morphology. Frozen tissue sections were maintained at room temperature for $30 \mathrm{~min}$, washed twice in $\mathrm{PB}$, followed by staining for NADPH-d with the addition of substrate $\beta$-NADPH [Malaysia Sigma-Aldrich (M) Sdn. Bhd, Kuala Lumpur, Malaysia] and nitroblue tetrazolium, a salt that yields an insoluble blue formazan precipitate visible under a light microscope (27). In the case of NADPH-d histochemistry controls, sections were incubated at room temperature for
45 min in a $\beta$-NADPH-free medium. The intensity of the reaction in the thymus and spleen was determined by measurement of optical density (OD; 0-260 nm), using Olympus cellSens (Olympus Soft Imaging Solutions GmbH, Münster, Germany) software version 1.6, and was graphically represented. From each sample, three to four slides were subjected to the staining procedure and multiple areas were evaluated randomly using a light microscope. The cross-sectional morphology of the tissues was observed using an Olympus BX41TF microscope (Olympus Corp., Tokyo, Japan). Images of the sections were captured using an Olympus UC30, with Olympus cellSens software version 1.6. All measurements were performed in duplicate or triplicate and repeated at least three times.

Statistical analysis. Statistical assessment of the intensity data was performed using one-way ANOVA followed by Bonferroni multiple comparison's tests (GraphPad Prism version 4.0; GraphPad Software, In., La Jolla, CA, USA). All numerical data are expressed as the mean \pm standard error of the mean and $\mathrm{P}<0.05$ was considered to indicate a statistically significant difference.

\section{Results}

NADPH-d expression in the thymus. Although the control group (DMSO-treated vehicle) received no drug treatment, weak or faint NADPH-d staining was observed in the cortex and medulla region of the thymus (Fig. 2A-C), whereas in the positive-control group (GTN), the capsule and cortex region demonstrated moderate NADPH-d expression 4 days after the GTN injection, which continuously increased at the eighth and twelfth day of treatment (Fig. 2D-F). This indicates that GTN induces time-dependent expression of NADPH-d in the thymus. However, the NADPH-d distribution was initially similar to that in the control group after day 4 , and subsequently the distribution spread to the whole lobule on the eighth and twelfth day of treatment.

Similarly, a gradual increase of NADPH-d distribution $(\mathrm{P}<0.001)$ was observed in the BetA treatment group and its activity increased along with longer BetA exposure (Fig. 2G-I). However, the thymus displayed only slight to moderate NADPH-d staining after 4 days (Fig. 2G), 8 days (Fig. 2H) and 12 days of BetA treatment (Fig. 2I), in the cortex and the medullary region. The interlobular septum extends from the capsule into the thymus, subdividing the thymus into interconnecting lobules, which are of varying size and orientation. The expression pattern of NADPH-d spread to a wider area at the medullary region across the septum 8 days after BetA treatment, demonstrating higher NADPH-d activity. As the septum is the site where blood vasculatures in the thymus are oriented, staining in this region (Fig. 2C and G) supports that NO has a role in vascular physiology. The graph (Fig. 2J) demonstrates the intensity (OD) per staining area $\left(\mathrm{cm}^{2}\right)$ of the thymus tissue sections after 4,8 and 12 days of treatment. Increased NADPH-d expression indicates that the effect of BetA on the thymus depends on exposure time.

NADPH-d expression in the spleen. Compared with that in the control group (Fig. 3A-C), the spleen of the GTN (Fig. 3D-F) and BetA groups (Fig. 3G-I) demonstrated a particularly 

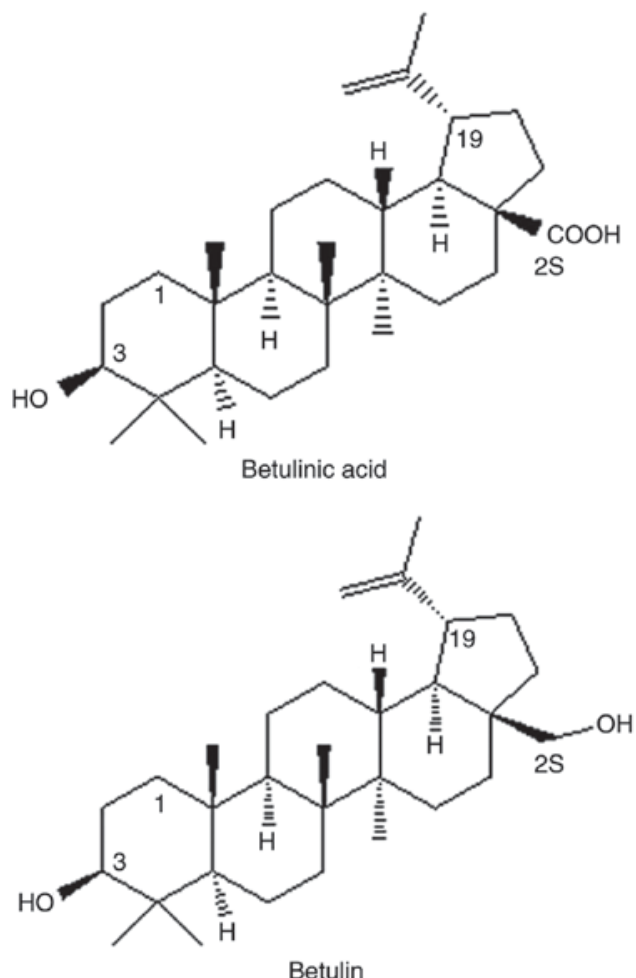

Figure 1. Structure of triterpenoid alcohol betulin and the corresponding carboxylic acid betulinic acid.

strong NADPH-d reaction, with increased expression levels in the cortex and medullary regions (Fig. 3D-I), as well as in the vasculature (Fig. 3C, F and I), which increased with longer exposure times. The spleen is enclosed by a fibro elastic outer connective tissue, the capsule, and composed of white and red pulp, forming two functionally and morphologically different units. The NADPH-d staining (brown precipitate) was more widely present in the red pulp than in the white pulp area. The red pulp region is comprised of various cells, including sinusoids (35). The graph (Fig. 3J) demonstrates the intensity (OD) per staining area $\left(\mathrm{cm}^{2}\right)$ of the spleen tissue sections after 4,8 and 12 days of treatment

Morphological changes. No phenotypical appearance or significant morphological changes were observed in either the GTN- or the BetA-treated thymus and spleen.

\section{Discussion}

The present study demonstrated positive NADPH-d staining in the thymus and in the spleen of non-immunized GTN and BetA-treated mice. However, its expression and distribution pattern varied with these agents throughout the treatment period. Although no morphological or phenotypical changes were evident in these organs, the NADPH-d activity was more prominent in the spleen than in the thymus. The red pulp region of the spleen strongly expressed NADPH-d, whereas only a moderate reactivity was observed in the white pulp region. Although NADPH-d expression was detected after 4 days, a significant increase in expression was observed after 8 days of BetA treatment, indicating the contribution of $\mathrm{NADPH}-\mathrm{d}$ in spleen $\mathrm{NO}$ generation during the entire treatment period. Similarly, a steady increase in NADPH-d activity in the thymus beginning from day 4 may specify an interactive outcome of $\mathrm{NO}$ on the thymus vascular and medulla regions, which may be involved in immune modulation (33,36-37). Although the function of NO in the thymus and spleen has not been demonstrated, the findings of the current study indicate that there is an association between the immunological effects induced by BetA. The major effect of BetA-induced $\mathrm{NO}$ appears to be involved in maintenance of the immune system (38-40) and the current results support other reports in which the presence of NO was demonstrated in the immune system $(33,41)$.

It has been demonstrated that the expression of NOS and production of $\mathrm{NO}$ are characteristic of cells involved in immune responses $(33,36,42)$. Although $\mathrm{NO}$ is less active in cells from normal mice (43), a spleen cell subpopulation produces enough NO during an in vitro immune response to completely prevent multiplication of $\mathrm{T}$ cells $(44,45)$. Similarly, previous studies have demonstrated that a wide range of potential immunomodulatory functions may be expected for NO in the thymus, including the following: Induction of tolerance, restriction of major histocompatibility complex, lymphocyte trafficking and regulation of thymic endocrine output $(33,36,37,42)$. Furthermore, if there are effects or changes in the cells due to BetA treatment, it is assumed that NO may be produced to perform its regulatory roles in the cells of these immune organs.

Betulin and BetA trigger and modify cytokine production in human whole blood cell cultures (46). To support this hypothesis, previous studies have reported that BetA augments mouse immune function, including cellular and humoral immunity, and activity of phagocytic macrophages $(39,47)$. BetA was identified as a modulatory agent of cytokine production by $\mathrm{T}$ helper cells (Th1/Th2) and other immune cells in animals. Consistently, the results of numerous studies indicated that BetA may be useful for modulation of the immune system (40,48-51). Furthermore, various bioactive materials derived from other plants exhibit immunomodulatory abilities (52-55).

In addition, $\mathrm{NO}$ is recognized to act as a vasodilator following its release from endothelial cells (56-58), including BetA-treated endothelial cells (59-62). This function is mediated by NO inhibitory action on vascular smooth muscles. However, Moncada et al $(25)$ and other studies $(63,64)$ have demonstrated that NO-mediated vasodilation occurs without endothelial cells present, where the NO-positive nitrergic nerves may act directly on smooth muscle cells, leading to vasodilation. Such control by neuronal NO has also been demonstrated in the peripheral nervous system $(65,66)$.

The innervation of NO-positive perivascular nerves has also been demonstrated in many types of vascular tissue (67-69). The distribution of supply of nerves in the thymus are not entirely known; however, previous studies focused on the neural structures contained within the thymus $(70,71)$. The activity of NADPH-d was demonstrated in many parts of the nervous system in mammals (72-74). The present results are consistent with previous findings that NADPH-d-labelled cells are present in the rat thymus $(28,30,75)$. Although the current study observed NADPH-d-stained nerve fibers in 

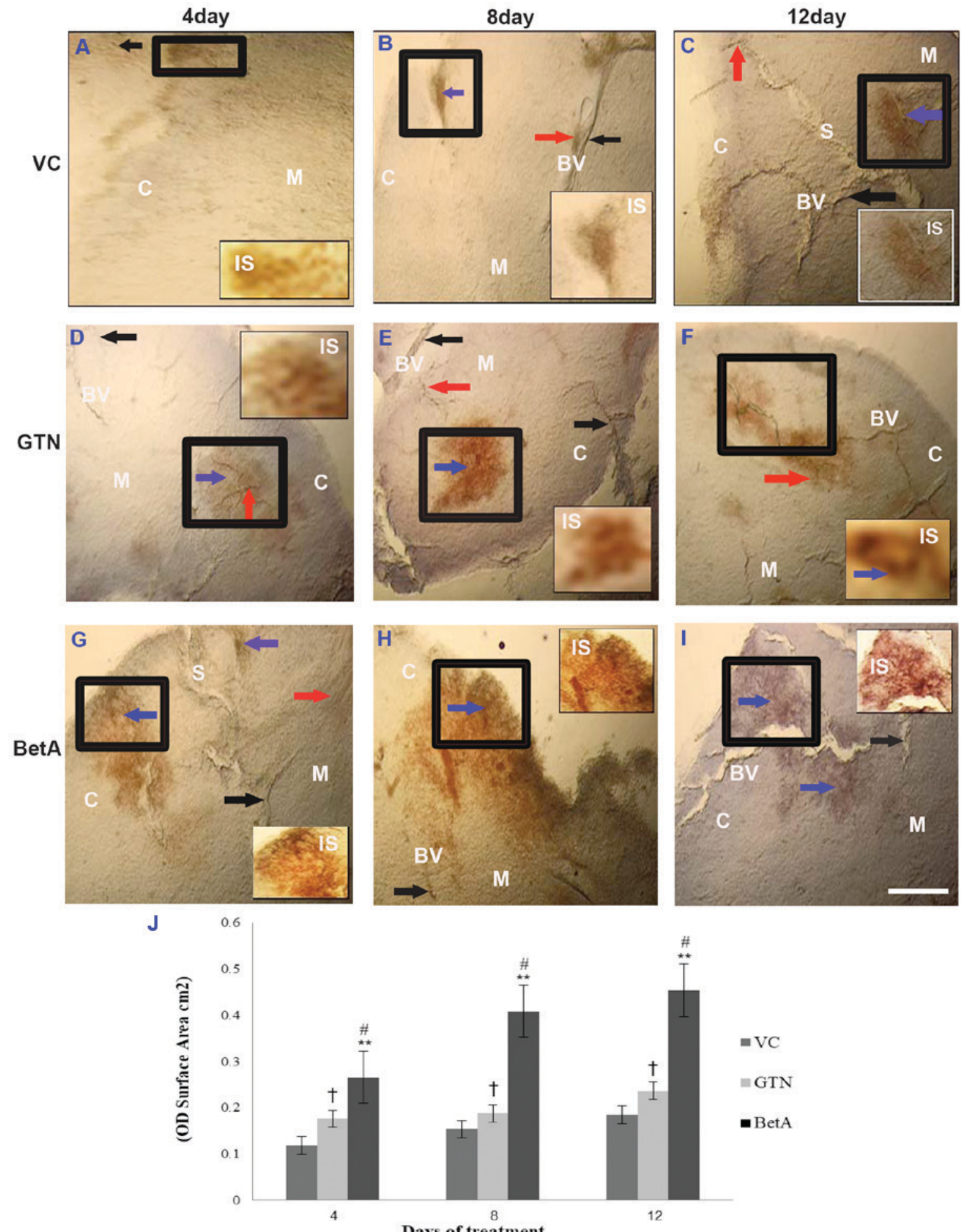

Days of treatment

Figure 2. Representative photomicrographs demonstrating thymus sections of the (A-C) VC (dimethyl sulfoxide), (D-F) positive (GTN) and (G-I) BetA-treated groups on days 4, 8 and 12 after treatment. Inset (IS) is representative of the area in the figure outlined in black. Black arrows identify the NADPH-d-stained blood vessels (BV), the red arrow points the perivascular nerve fibres and blue arrow demonstrates the NADPH-d positive cells in the cortex (denoted by the letter C) and medulla (denoted by the letter M). The letter 'S' indicates the interlobular septum. Scale bar, $100 \mu \mathrm{m}$. (J) The intensity (OD) of the NADPH-d staining was quantified using Olympus Soft Imaging cellSens software version 1.6. Data are expressed as means \pm standard deviation of mice ( $\mathrm{n}=6 \mathrm{per}$ group) ${ }^{* *} \mathrm{P}<0.001$ vs. the VC group, ${ }^{\#} \mathrm{P}<0.001$ vs. the GTN group. $\dagger \mathrm{P}<0.01$ vs. the VC group. GTN, goniothalamin; BetA, betulinic acid; NADPH-d, nicotinamide adenine dinucleotide phosphate diaphorase; VC, vehicle control; OD, optical density.

the perivascular area, no NADPH-d neuronal cell body-like structures were observed in either the thymus or the spleen. The moderate distribution of NO-containing nerves travelling along blood vessels may reflect a particularly significant role that neuronal NO may perform in controlling blood flow through the thymus and spleen. The fact that NO-positive nerves and the vascular endothelium may produce NO to influence blood flow has been described in the nervous 

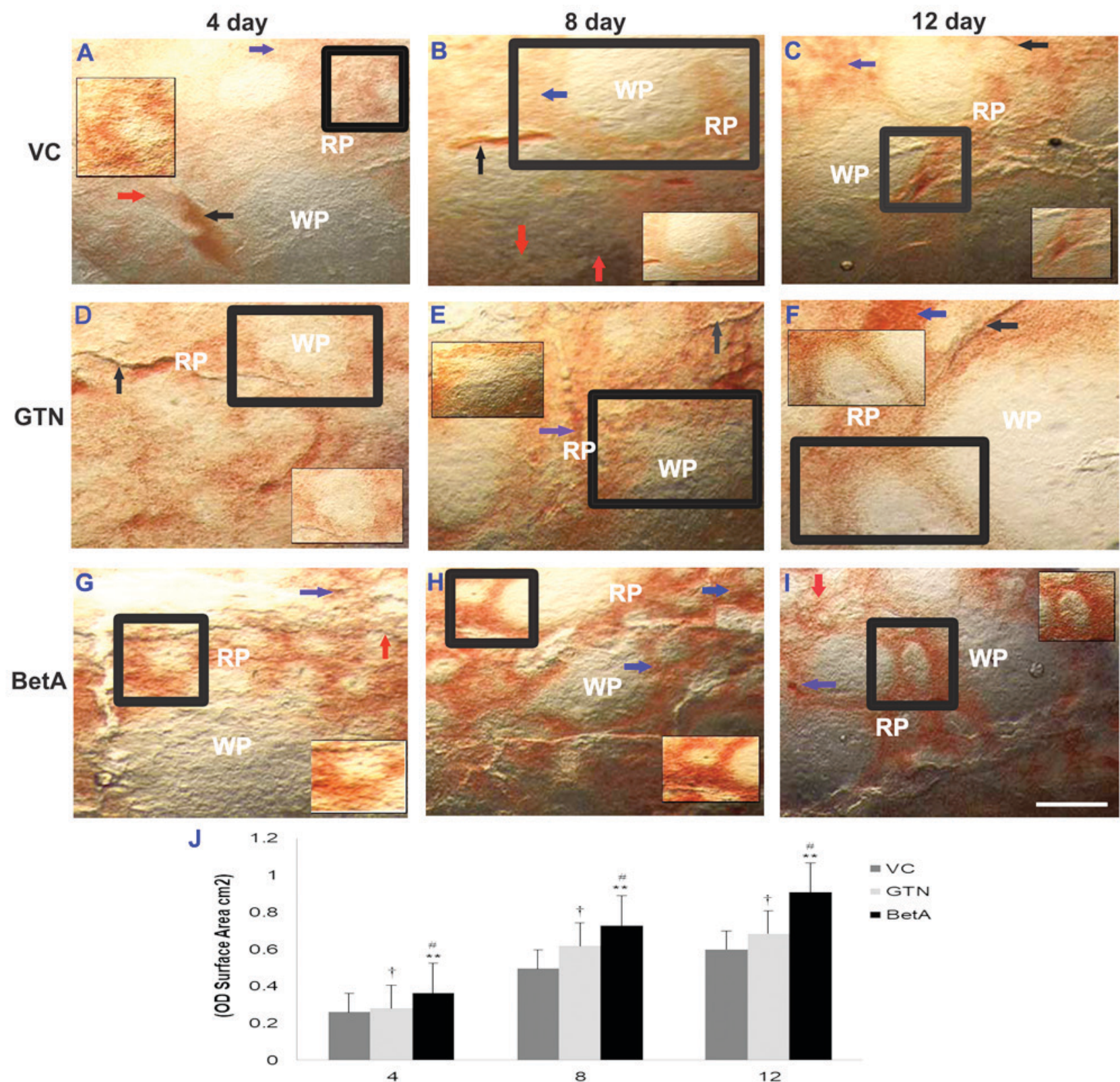

Days of treatment

Figure 3. Representative photomicrographs demonstrating spleen sections the (A-C) VC (dimethyl sulfoxide), (D-F) positive (GTN) and (G-I) BetA-treated groups on days 4,8 and 12 after treatment. Inset (IS) is representative of the area in the figure outlined in black. Black arrows identify the NADPH-d-stained blood vessels (BV), the red arrow points the perivascular nerve fibres and blue arrow demonstrates the NADPH-d positive cells in the red pulp (RP) region. 'WP' indicates the white pulp region. Scale bar, $100 \mu \mathrm{m}$. (J) The intensity (OD) of the NADPH-d staining was quantified using Olympus Soft Imaging cellSens software version 1.6. Data are expressed as means \pm standard deviation of mice ( $\mathrm{n}=6$ per group) ${ }^{* *} \mathrm{P}<0.001$ vs. the VC group, ${ }^{\text {"P }}<0.001$ vs. the GTN group, ${ }^{\dagger} \mathrm{P}<0.01$ vs. the VC group. GTN, goniothalamin; BetA, betulinic acid; NADPH-d, nicotinamide adenine dinucleotide phosphate diaphorase; VC, vehicle control; OD, optical density.

system (74), pancreas (76), thyroid $(27,29)$ and various other tissues. This observation indicates that NO participates in neurotransmission in the thymus and spleen. It is important to note that in addition to blood vessels, NO may regulate the secretory activity of immune cells by its generation in these cells (77). Thus, BetA may present a promising biological response modifier and may reinforce the immune response of a host.

In conclusion, the current study demonstrates that BetA treatment induces the expression of NADPH-d activity in the thymus and spleen without causing any significant changes to the morphology of the organs. These findings are of direct clinical relevance and may contribute to the progression of drug discovery. To the best of our knowledge, this is the most significant study describing BetA-induced, NADPH-d-mediated NO signaling, which may be the mechanism underlying BetA-elicited immunomodulation in these organs.

\section{Acknowledgements}

The present study was partly supported by an internal research grant (grant no. 1437-0195) obtained from the Deanship of Scientific Research University of Tabuk (Tabuk, Saudi Arabia). 


\section{References}

1. Geetha S, Singh V, Ram MS, Ilavazhagan G, Banerjee PK and Sawhney RC: Immunomodulatory effects of seabuckthorn (Hippophae rhamnoides L.) against chromium (VI) induced immunosuppression. Mol Cell Biochem 278: 101-109, 2005.

2. Aravindaram K and Yang NS: Anti-inflammatory plant natural products for cancer therapy. Planta Med 76: 1103-1117, 2010

3. Winkler C, Wirleitner B, Schroecksnadel K, Schennach H, Mur E and Fuchs D: In vitro effects of two extracts and two pure alkaloid preparations of Uncaria tomentosa on peripheral blood mononuclear cells. Planta Med 70: 205-210, 2004.

4. Patwardhan B and Gautam M: Botanical immunodrugs: Scope and opportunities. Drug Discov Today 10: 495-502, 2005.

5. Sreesha T: In-vitro study of cytotoxicity activity of flavonoid fraction from the petals of Cassia senna. Int $\mathbf{J}$ Ethnomed Pharmacol Res 1: 52-55, 2013.

6. Nagarathna PKM, Reena K, Sriram Reddy and Johnson W: Review on immunomodulation and immunomodulatory activity of some herbal plants. Int J Pharm Sci Rev Res 22: 223-230, 2013

7. Ibrahim J, Waqas A and Syed Nasir AB: Plant-derived immunomodulators: An insight on their preclinical evaluation and clinical trials. Front Plant Sci 6: 655, 2015.

8. Schepetkin IA and Quinn MT: Botanical polysaccharides: Macrophage immunomodulation and therapeutic potential. Int Immunopharmacol 6: 317-333, 2006.

9. Eiznhamer DA and Xu ZQ: Betulinic acid: A promising anticancer candidate. IDrugs 7: 359-373, 2004.

10. Higa M, Noha N, Yokaryo H, Ogihara K and Yogi S: Three new naphthoquinone derivatives from Diospyros maritima Blume. Chem Pharm Bull (Tokyo) 50: 590-593, 2002.

11. Hanson JR: Pentacyclic triterpenes as promising agents in cancer. Salvador JAR (ed). Nova Science Publishers, Inc, New York, NY, p191, 2010

12. Santos RC, Salvador JA, Marín S, Cascante M, Moreira JN and Dinis TC: Synthesis and structure-activity relationship study of novel cytotoxic carbamate and $\mathrm{N}$-acylheterocyclic bearing derivatives of betulin and betulinic acid. Bioorg Med Chem 18 : 4385-4396, 2010

13. Zhang DM, Xu HG, Wang L, Li YJ, Sun PH, Wu XM, Wang GJ, Chen WM and Ye WC: Betulinic acid and its derivatives as potential antitumor agents. Med Res Rev 35: 1127-1155, 2015.

14. Ali-Seyed M, Jantan I, Vijayaraghavan K and Bukhari SN Betulinic acid: Recent advances in chemical modifications, effective delivery, and molecular mechanisms of a promising anticancer therapy. Chem Biol Drug Des 87: 517-536, 2016.

15. Alakurtti S, Mäkelä T, Koskimies S and Yli-Kauhaluoma J: Pharmacological properties of the ubiquitous natural product betulin. Eur J Pharm Sci 29: 1-13, 2006

16. Csuk R: Betulinic acid and its derivatives: A patent review (2008-2013). Expert Opin Ther Pat 24: 913-923, 2014.

17. Zuco V, Supino R, Righetti SC, Cleris L, Marchesi E, Gambacorti-Passerini C and Formelli F: Selective cytotoxicity of betulinic acid on tumor cell lines, but not on normal cells. Cancer Lett 175: 17-25, 2002.

18. Thurnher D, Turhani D, Pelzmann M, Wannemacher B, Knerer B, Formanek M, Wacheck V and Selzer E: Betulinic acid: A new cytotoxic compound against malignant head and neck cancer cells. Head Neck 25: 732-740, 2003.

19. Mukherjee R, Kumar V, Srivastava SK, Agarwal SK and Burman AC: Betulinic acid derivatives as anticancer agents: Structure activity relationship. Anticancer Agents Med Chem 6: 271-279, 2006.

20. Galgon T, Wohlrab W and Dräger B: Betulinic acid induces apoptosis in skin cancer cells and differentiation in normal human keratinocytes. Exp Dermatol 14: 736-743, 2005.

21. Selzer E, Pimentel E, Wacheck V, Schlegel W, Pehamberger H, Jansen B and Kodym R: Effects of betulinic acid alone and in combination with irradiation in human melanoma cells. J Invest Dermatol 114: 935-940, 2000.

22. Periasamy G, Teketelew G, Gebrelibanos M, Sintayehu B, Gebrehiwot M, Karim A and Geremedhin G: Betulinic acid and its derivatives as anti-cancer agent: A review. Arch Appl Sci Res 6: 47-58, 2014

23. Mullauer FB, Kessler JH and Medema JP: Betulinic acid, a natural compound with potent anticancer effects. Anticancer Drugs 21: 215-227, 2010.
24. Heiss EH, Kramer MP, Atanasov AG, Beres H, Schachner D and Dirsch VM: Glycolytic switch in response to betulinic acid in non-cancer cells. PLoS One 9: e115683, 2014.

25. Moncada S, Palmer RM and Higgs A: Nitric oxide: Physiology, pathophysiology and pharmacology. Pharmacol Rev 43: 109-142, 1991.

26. Knowles RG and Moncada S: Nitric oxide synthase in mammals. Biochemical J 298: 249-258, 1994.

27. Syed MA, Leong SK and Chan AS: Localization of NADPH-diaphorase reactivity in the chick and mouse thyroid gland. Thyroid 4: 475-478, 1994.

28. Gulati P, Leong SK and Chan AS: Ontogeny of NADPH-d expression in the thymic microenvironment of the chick embryo. Cell Tissue Res 294: 335-343, 1998.

29. Akbari Z, Rohani MH and Behzadi G: NADPH-d/NOS reactivity in the lumbar dorsal horn of congenitally hypothyroid pups before and after formalin pain induction. Int J Dev Neurosci 27: 779-787, 2009.

30. Förstermann U and Sessa WC: Nitric oxide synthases: Regulation and function. Eur Heart J 33: 829-837, 837a-837d, 2012.

31. Andronowska A and Chruściel M: Expression and cellular distribution of NADPH-diaphorase and nitric oxide synthases in the porcine uterus during early pregnancy. Folia Histochem Cytobiol 45: 375-380, 2007

32. Ali SM, Chan AS and Leong SK: Localization of nitrergic neuronal and non-neuronal cells in the ultimobranchial glands of the chicken. Anat Embryol (Berl) 193: 161-168, 1996.

33. Dorko F, Špakovská T, Lovasová K, Patlevič P and Kluchová D: NADPH-d activity in rat thymus after the application of retinoid acid. Eur J Histochem 56: e7, 2012.

34. Hope BT, Michael GJ, Knigge KM and Vincent SR: Neuronal NADPH diaphorase is a nitric oxide synthase. Proc Natl Acad Sci USA 88: 2811-2814, 1991.

35. Steiniger BS: Human spleen microanatomy: Why mice do not suffice. Immunology 145: 334-346, 2015.

36. Danko J, Ondrasovic M, Svický E, Jenca A, Pospieszny N and Ondrasovicová O: Histochemical study of innervation and NADPH-D activity of the thymus. Anat Histol Embryol 32: 233-235, 2003

37. Svický E, Ondraovic M, Danko J, Ondrasovicová O, Jenca A, Pospieszny $\mathrm{N}$ and Toropila M: Localisation of NADPH-diaphorase-positive structures in the thymus of the rat, mouse and rabbit. Folia Morphol (Warsz) 62: 167-170, 2003.

38. Jacobs AT and Ignarro LJ: Lipopolysaccharide-induced expression of interferon-beta mediates the timing of inducible nitric-oxide synthase induction in RAW 264.7 macrophages. J Biol Chem 276: 47950-47957, 2001.

39. Yi JE, Obminska-Mrukowicz B, Yuan LY and Yuan $\mathrm{H}$ : Immunomodulatory effects of betulinic acid from the bark of white birch on mice. J Vet Sci 11: 305-313, 2010.

40. Jine Y, Lis M, Szczypka M and Obmińska-Mrukowicz B: Influence of betulinic acid on lymphocyte subsets and humoral immune response in mice. Pol J Vet Sci 15: 305-313, 2012.

41. Hibbs JB Jr: Infection and nitric oxide. J Infect Dis 185 (Suppl 1): S9-S17, 2002.

42. Ibiza S and Serrador JM: The role of nitric oxide in the regulation of adaptive immune responses. Immunología 27: 103-117, 2008.

43. Filep JG, Földes-Filep E, Rousseau A, Sirois P and Fournier A: Vascular responses to endothelin-1 following inhibition of nitric oxide synthesis in the conscious rat. Br J Pharmacol 110: 1213-1221, 1993.

44. Umeshappa CS, Singh KP, Nanjundappa RH, Channappanavar R, Maan S and Maan NS: Bluetongue virus-23 stimulates inducible nitric oxide synthase expression and nitric oxide production in mononuclear cells of blood and/or regional lymphoid organs. Vet Res Commun 36: 245-250, 2012.

45. Darwiche SS, Pfeifer R, Menzel C, Ruan X, Hoffman M, Cai C, Chanthaphavong RS, Loughran P, Pitt BR, Hoffman R, et al: Inducible nitric oxide synthase contributes to immune dysfunction following trauma. Shock 38: 499-507, 2012.

46. Zdzisińska B, Rzeski W, Paduch R, Szuster-Ciesielska A, Kaczor J, Wejksza K and Kandefer-Szerszeń M: Differential effect of betulin and betulinic acid on cytokine production in human whole blood cell cultures. Pol J Pharmacol 55: 235-238, 2003.

47. Chen S, Bai Y, Li Z, Jia K, Jin Y, He B, Qiu WW, Du C, Siwko S, Chen H, et al: A betulinic acid derivative SH479 inhibits collagen-induced arthritis by modulating T cell differentiation and cytokine balance. Biochem Pharmacol 126: 69-78, 2017. 
48. Sultana N and Saify ZS: Naturally occurring and synthetic agents as potential anti-inflammatory and immunomodulants. Antiinflamm Antiallergy Agents Med Chem 11: 3-19, 2012.

49. Wang P, Li Q, Li K, Zhang X, Han Z, Wang J, Gao D and Li J: Betulinic acid exerts immunoregulation and anti-tumor effect on cervical carcinoma (U14) tumor-bearing mice. Pharmazie 67: 733-739, 2012

50. Dash SK, Chattopadhyay S, Tripathy S, Dash SS, Das B, Mandal D, Mahapatra SK, Bag BG and Roy S: Self-assembled betulinic acid augments immunomodulatory activity associates with IgG response. Biomed Pharmacother 75: 205-217, 2015.

51. Yi J, Zhu R, Wu J, Wu J, Xia W, Zhu L, Jiang W, Xiang S and Tan Z: In vivo protective effect of betulinic acid on dexamethasone induced thymocyte apoptosis by reducing oxidative stress. Pharmacol Rep 68: 95-100, 2016.

52. Kovalenko LP, Balakshin VV, Presnova GA, Chistyakov AN, Shipaeva EV, Alekseeva SV and Durnev AD: Immunotoxicity and allergenic properties of betulin-containing birch bark dry extract. Pharm Chem J 41: 17-19, 2007.

53. Naithani R, Huma LC, Moriarty RM, McCormick DL and Mehta RG: Comprehensive review of cancer chemopreventive agents evaluated in experimental carcinogenesis models and clinical trials. Curr Med Chem 15: 1044-1071, 2008.

54. Paszkiewicz M, Budzyńska A, Różalska B and Sadowska B: The immunomodulatory role of plant polyphenols. Postepy Hig Med Dosw (Online) 66: 637-636, 2012 (In Polish).

55. Mathew NS and Negi PS: Traditional uses, phytochemistry and pharmacology of wild Banana (Musa acuminata Colla): A review. J Ethnopharmacol 196: 124-140, 2017.

56. Schmidt A, Bilgasem S, Lorkowski S, Vischer P, Völker W Breithardt G, Siegel G and Buddecke E: Exogenous nitric oxide regulates activity and synthesis of vascular endothelial nitric oxide synthase. Eur J Clin Invest 38: 476-485, 2008.

57. Son Y, Lee JH, Cheong YK, Jung HC, Jeong SO, Park SH and Pae HO: Piceatannol, a natural hydroxylated analog of resveratrol, promotes nitric oxide release through phosphorylation of endothelial nitric oxide synthase in human endothelial cells. Eur Rev Med Pharmacol Sci 19: 3125-3132, 2015.

58. Tillery LC, Epperson TA, Eguchi S and Motley ED: Differential regulation of endothelial nitric oxide synthase phosphorylation by protease-activated receptors in adult human endothelial cells. Exp Biol Med (Maywood) 241: 569-580, 2016.

59. Steinkamp-Fenske K, Bollinger L, Xu H, Yao Y, Horke S, Förstermann U and Li H: Reciprocal regulation of endothelial nitric-oxide synthase and NADPH oxidase by betulinic acid in human endothelial cells. J Pharmacol Exp Ther 322: 836-842, 2007.

60. Qian LB, Fu JY, Cai X and Xia ML: Betulinic acid inhibits superoxide anion-mediated impairment of endothelium-dependent relaxation in rat aortas. Ind J Pharmacol 44: 588-592, 2012.

61. Hohmann N, Xia N, Steinkamp-Fenske K, Förstermann U and $\mathrm{Li} \mathrm{H}$ : Estrogen receptor signaling and the PI3K/Akt pathway are involved in betulinic acid-induced eNOS activation. Molecules 21: E973, 2016.

62. Jin SW, Choi CY, Hwang YP, Kim HG, Kim SJ, Chung YC, Lee KJ, Jeong TC and Jeong HG: Betulinic acid increases eNOS phosphorylation and no synthesis via the calcium-signaling pathway. J Agric Food Chem 64: 785-791, 2016.
63. Chen MF, Huang YC, Long C, Yang HI, Lee HC, Chen PY, Hoffer BJ and Lee TJ: Bimodal effects of fluoxetine on cerebral nitrergic neurogenic vasodilation in porcine large cerebral arteries. Neuropharmacology 62: 1651-1658, 2012.

64. Lies B, Beck K, Keppler J, Saur D, Groneberg D and Friebe A: Nitrergic signalling via interstitial cells of Cajal regulates motor activity in murine colon. J Physiol 593: 4589-4601, 2015.

65. Wenisch S and Arnhold S: NADPH-diaphorase activity and NO synthase expression in the olfactory epithelium of the bovine. Anat Histol Embryol 39: 201-206, 2010.

66. Selaru M, Rusu MC and Jianu AM: Expression of nNOS in the human larynx. Anat Sci Int 90: 327-330, 2015.

67. Knipping S, Holzhausen HJ, Berghaus A, Bloching $M$ and Riederer A: Ultrastructural detection of nitric oxide in human nasal mucosa. Otolaryngol Head Neck Surg 132: 620-625, 2005.

68. Koyama T, Hatanaka Y, Jin X, Yokomizo A, Fujiwara H, Goda M, Hobara N, Zamami Y, Kitamura Y and Kawasaki H: Altered function of nitrergic nerves inhibiting sympathetic neurotransmission in mesenteric vascular beds of renovascular hypertensive rats. Hypertens Res 33: 485-491, 2010.

69. Shimada S, Todoki K, Omori Y, Toyama T, Matsuo M, Wada-Takahashi S, Takahashi SS and Lee MC: Contribution of nitrergic nerve in canine gingival reactive hyperemia. J Clin Biochem Nutr 56: 98-104, 2015.

70. Mignini F, Sabbatini M, D'Andrea V and Cavallotti C: Intrinsic innervation and dopaminergic markers after experimental denervation in rat thymus. Eur J Histochem 54: e17, 2010.

71. Dorko F, Danko J, Flešárová S, Boroš E and Sobeková A: Effect of pesticide bendiocar-bamate on distribution of acetylcholineand butyrylcholine-positive nerves in rabbit's thymus. Eur J Histochem 55: e37, 2011.

72. Liu C, Yang Y, Hu X, Li JM, Zhang XM, Cai Y, LiZ and Yan XX: Ontogenesis of NADPH-diaphorase positive neurons in guinea pig neocortex. Front Neuroanat 9: 11, 2015.

73. Jung J, Na C and Huh Y: Alterations in nitric oxide synthase in the aged CNS. Oxid Med Cell Longev 2012: 718976, 2012.

74. Cossenza M, Socodato R, Portugal CC, Domith IC, Gladulich LF, Encarnação TG, Calaza KC, Mendonça HR, Campello-Costa P and Paes-de-Carvalho R: Nitric oxide in the nervous system: Biochemical, developmental, and neurobiological aspects. Vitam Horm 96: 79-125, 2014.

75. Downing JE: Multiple nitric oxide synthase systems in adult rat thymus revealed using NADPH diaphorase histochemistry. Immunology 82: 659-664, 1994.

76. Villanueva C and Giulivi C: Subcellular and cellular locations of nitric-oxide synthase isoforms as determinants of health and disease. Free Radic Biol Med 49: 307-316, 2010.

77. Bogdan C: Nitric oxide synthase in innate and adaptive immunity: An update. Trends Immunol 36: 161-178, 2015.

(i) $\Theta$ This work is licensed under a Creative Commons Attribution-NonCommercial-NoDerivatives 4.0 International (CC BY-NC-ND 4.0) License. 